Egyptian

Orthodontic Journal

\title{
PAIN IN ORTHODONTIC TREATMENT IN THREE DIFFERENT AGE GROUPS.
}

\author{
Ahmed R. Afify*, Ahmed A. El-Bialy**, Yasser L. A. Mahmoud ${ }^{* * *}$ \\ ABSTRACT
}

The feeling of pain as a result of orthodontic tooth movement is one of the most cited negative side effects associated with orthodontic treatment. Pain intensity ranges from a slight soreness to a severe constant, throb6ing pain.

The purpose of the present investigation was to assess pain experiences during the initial stages of orthodontic treatment in terms of level and duration. Also to relate these assessments to the different age ranges.

The subject material comprised 45 female patients with an age range of 11 - 39 years with Class I, crowding. All patients were treated by extraction four first bicuspids with the Straight-wire technique $0.018^{\prime \prime} \times 0.025^{\prime \prime}$ Roth prescription system. Subjects were divided into 3 equal groups based on their age.

Following the placement and ligation of the first archwire (Nickel titanium 0.014" alloy archwire) subjective assessments of pain were made by means of a 100-mm visual analogue scale (VAS) after two hours and then every 24 hours over the first 7-days. Results revealed the following:

1- All patients experienced pain during treatment.

2- Pain was initiated in the majority of cases after 2 hours and peaked after 24 hours in $100 \%$ of cases then descended by the third day.

*Assistant Professor of Orthodontics, Faculty of Dentistry,Mansoura University. Egypt

${ }^{* *}$ Assistant Professor of Orthodontics, Faculty of Dentistry, Mansoura University.Egypt

${ }^{* * *}$ Lecturer of Orthodontics, Faculty of Dentistry,Mansoura University.Egypt 
Egyptian

Orthodontic Journal

\section{3- There was no statistically significant difference in pain perception} among the three age groups although the mean of pain experience was always the highest in the eldest group.

\section{4- At seventh day, 35\%of the patients still recorded pain.}

\section{INTRODUCTION}

Orthodontic patients usually are informed that there may be some discomfort or little pain associated with the insertion of the initial arch wires, and during periodic adjustment of orthodontic appliances. However, the intensity and duration of discomfort may not always be discussed.

The fear of pain has been reported as an important factor in discouraging patients from seeking orthodontic treatment ${ }^{1}$. Jones and $\mathrm{Chan}^{2}$ showed that compliance with orthodontic treatment may be predicated on the amount of initial pain and discomfort experienced.

The cause of the pain resulting from orthodontic tooth movement is not entirely clear. Furstman and Bernik ${ }^{3}$ suggested that periodontal pain was caused by a process of pressure, ischemia, inflammation, and edema. Soltis, Nakfoor and Bowman ${ }^{4}$, in an experiment to measure the subjective ability of orthodontic patients to distinguish differences in the intensity of force applied to the maxillary incisors, found that the proprioceptive and discriminatory abilities of patients were reduced 4 days after the insertion of orthodontic appliances. The patient discomfort was attributed to the lowering of the pain threshold and disruption of the normal mechanisms associated with proprioception input from the nerve endings in the periodontal ligament.

Fujita ${ }^{5}$ reported changes in the maximum tolerance of persons when their teeth undergo orthodontic tooth movement.

Burstone $^{6}$, in a study examining the pain caused by orthodontic appliances, noted that there was a wide range of individual responses when similar forces were applied to the teeth. He identified an immediate and delayed pain response. He speculated that the former was related to the initial compression of the periodontal ligament immediately after the placement of the arch wire. The latter response, which started a few hours later, was termed hyperalgesia of the periodontal ligament.

Jones $^{7}$ examined the discomfort experience of patients following the placement of an initial archwire. The discomfort was measured over a 16-day 
period by means of a verbal rating scale and analgesic consumption methods concurrently. The findings indicated that a large proportion of the sample suffered moderate to severe discomfort over the first few days and that adults had a statistically higher discomfort experience than adolescents. There was no statistical difference between the sexes in the discomfort experience.

Jones and Richmond ${ }^{8}$, investigated the relationship between the total discomfort experienced and the degree of crowding in a sample consisted of 24 patients, who had previously completed a discomfort index card for the first 16 days following placement of a fixed appliance. He found no correlation between the total discomforts experienced and the degree of crowding.

Among existing studies of pain in orthodontics, a great variety of findings concerning the duration of pain are reported. Ngan et al. ${ }^{9}$ found that the perception of discomfort after insertion of separators or archwire decreased to placement level in $7^{\text {th }}$ day. Scheurer et al. ${ }^{10}$, reported that $25 \%$ of investigated patients still reported pain $7^{\text {th }}$ day after insertion of a fixed appliance.

The pain intensity generally increases with time, according to measurements at $4 \mathrm{~h}$ and $24 \mathrm{~h}$, but falls to rather normal levels after 7 days., ${ }^{2,10,11}$

Leavitt et al ${ }^{12}$. studied the relationship to pulpal sensitivity as measured by electrical stimulation and subjective reports of tooth pain after archwire insertion. He concluded that greater orthodontic tooth pain were associated with increased sensitivity to electrical stimulation.

The methods that were used for pain measurement treated pain as though it were a single unique quality that varies only in intensity ${ }^{13}$. These methods include the use of verbal rating scales (VRSs), numerical rating scales (NRSs) and visual analogue scales (VASs). Although VRSs and NRSs are simple to administer and have demonstrated reliability and validity, the advantages associated with VASs make them the measurement instrument of choice. The most common VAS consists of a 10 -cm horizontal ${ }^{14,15}$ or vertical line ${ }^{16}$ with the two endpoints labeled 'no pain' and 'worst pain'. The patient is instructed to place a mark on the $10-\mathrm{cm}$ line at a point which corresponds to the level of pain intensity he presently feels. The distance in centimeters from the low end of the VAS to the patient's mark is used as a numerical score of the severity of pain.

Many ways have been reported for the control of orthodontic pain. These include therapeutic ${ }^{10,17,18}$ and non-therapeutic ${ }^{19}$ means. Proffit ${ }^{19}$ recommended biting of a plastic wafer or a chewing gum during the first 8 hours following an orthodontic adjustment to increase the blood flow in a compressed ligament area, thereby preventing build-up of metabolic products that stimulate pain receptors. 
The aim of the present study was to assess pain experiences during the initial stages of orthodontic treatment in terms of level and duration. Also to relate these assessments to the different age ranges of the patients.

\section{Materials And Methods}

The subject material comprised 45 female patients with a Class I, malocclusion treated by extraction of four first premolars. All attended to Faculty of Dentistry, King Abdul-Aziz University (KAAU), Jeddah, K.S.A seeking orthodontic treatment. The criteria for selection were:

1. All the patients have Angle's class I crowding.

2. Full permanent dentition except for the wisdom teeth.

3. All the patients have no previous orthodontic treatment.

4. No dental problems that may induce any pain during treatment.

Complete orthodontic records were done for each patient and a treatment plan was established. These records included: Study casts lateral cephalogram, panoramic view and intra- and extra-oral photographs.

Full fixed Roth straight wire appliances 0.018 " x 0.025 " slot were used for treatment. Appliances were placed in both arches then leveling and alignment were accomplished through sequential increase in archwire dimensions starting from 0.014 " round titanium wire.

Subjects were divided into 3 groups based on their age range as follows: Group 1: consisted of 15 patients and ranged in age from 11Ys 3 Ms to 18 Ys 6 Ms with a mean age of 14 Ys 4 Ms. - Group 2: consisted of 15 patients and ranged in age from 18 Ys 9 Ms to 26 Ys 8 Ms with a mean age of 22 Ys 7Ms . - Group 3: consisted of 15 patients and ranged in age from 27 Ys 5 Ms to 38 Ys 6 Ms with a mean age of 31 Ys $4 \mathrm{Ms}$.

Assessments of pain/discomfort was made by means of a $100 \mathrm{~mm}$ Visual Analogue Scale (VAS) after the insertion and ligation of the first archwire (0.014" Niti) . The first arch was inserted at least 10 days after extraction .The VAS is a line whose ends are anchored and defined with appropriate verbal descriptors such as "no pain" or "severe pain." The patient is asked to mark the line at a point representing the severity of their pain. The distance of the mark from the end of the scale is then taken to represent pain severity or the "pain score." Each subject was given eight VAS scoring slips and instructed to 
evaluate pain that they may feel following the placement of the first archwire (Nickel titanium 0.014" alloy arch wire) after two hours and then every 24 hours for seven days by marking the spot on the line they believed to best represent the pain they were experiencing at the time. The VAS score is the distance from the line end (zero score) to the point of the subject's mark, measured to the nearest millimeter. Subjects were instructed to make each evaluation independently from the previous ones by not consulting the previous VAS ratings. Subjects were also instructed not to use any analgesics or pain killers. Results were omitted for any subject who reported the use of any pain killers.

\section{Statistical analysis}

Data were saved on an Excel spreadsheet and then transferred to SPSS software package (SPSS for Windows 98, version 10.0, SPSS Inc, Chicago, Ill) for statistical analysis. A one-way analysis of variance was performed on the VAS measurements in the three groups to discover if there were any significant differences among the groups.

\section{RESULTS}

Forty five female subjects were included in this study divided into three age groups Table 1 .

Analysis of variance (ANOVA) was used to find the differences in pain intensity among the three groups. The results of ANOVA demonstrated no significant differences in mean pain intensity at the eight periods studied. Mean pain scores and standard deviations are given in Table 2.

Peak pain occurred at 24 hours (Figure 1). Pain levels started to decrease gradually from the peak pain to seven days after the insertion of the archwires.

Table 1: Age Range and Mean Age of the Three Groups.

\begin{tabular}{|c|c|c|c|}
\hline Group & Number & Age Range & Mean Age \\
\hline G 1 & 15 & 11 Ys 3 Ms - 18 Ys 6 Ms & 14 Ys 4 Ms \\
\hline G 2 & 15 & 18 Ys 9 Ms - 26 Ys 8 Ms & 22 Ys 7Ms \\
\hline G 3 & 15 & 27 Ys 5 Ms - 38 Ys 7 Ms & 31 Ys 11Ms \\
\hline
\end{tabular}


Table 2: Mean Pain Score and Standard Deviation of the Three Groups.

\begin{tabular}{|c|c|c|c|c|c|c|c|c|}
\hline Groups & $\begin{array}{c}\text { Two } \\
\text { Hours }\end{array}$ & $\begin{array}{c}\text { One } \\
\text { Day }\end{array}$ & $\begin{array}{c}\text { Two } \\
\text { Days }\end{array}$ & $\begin{array}{c}\text { Three } \\
\text { Days }\end{array}$ & $\begin{array}{c}\text { Four } \\
\text { Days }\end{array}$ & $\begin{array}{c}\text { Five } \\
\text { Days }\end{array}$ & $\begin{array}{c}\text { Six } \\
\text { Days }\end{array}$ & $\begin{array}{c}\text { Seven } \\
\text { Days }\end{array}$ \\
\hline G 1 & $\begin{array}{c}2.82 \pm \\
0.81\end{array}$ & $\begin{array}{c}5.64 \pm \\
0.45\end{array}$ & $\begin{array}{c}4.68 \pm \\
0.50\end{array}$ & $\begin{array}{c}4.16 \pm \\
0.44\end{array}$ & $\begin{array}{c}3.77 \pm \\
0.37\end{array}$ & $\begin{array}{c}3.39 \pm \\
0.29\end{array}$ & $\begin{array}{c}2.27 \pm \\
0.30\end{array}$ & $\begin{array}{c}0.95 \pm \\
0.72\end{array}$ \\
\hline G 2 & $\begin{array}{c}2.63 \pm \\
1.29\end{array}$ & $\begin{array}{c}5.47 \pm \\
0.35\end{array}$ & $\begin{array}{c}4.75 \pm \\
0.41\end{array}$ & $\begin{array}{c}4.39 \pm \\
0.55\end{array}$ & $\begin{array}{c}3.74 \pm \\
0.53\end{array}$ & $\begin{array}{c}3.02 \pm \\
0.68\end{array}$ & $\begin{array}{c}2.38 \pm \\
0.68\end{array}$ & $\begin{array}{c}0.97 \pm \\
0.95\end{array}$ \\
\hline G 3 & $3.17 \pm$ \\
1.00 & $\begin{array}{c}5.85 \pm \\
0.48\end{array}$ & $\begin{array}{c}5.09 \pm \\
0.56\end{array}$ & $\begin{array}{c}4.41 \pm \\
0.60\end{array}$ & $\begin{array}{c}3.53 \pm \\
0.56\end{array}$ & $\begin{array}{c}2.9 \pm \\
0.62\end{array}$ & $\begin{array}{c}2.31 \pm \\
0.62\end{array}$ & $\begin{array}{c}0.84 \pm \\
0.95\end{array}$ \\
\hline
\end{tabular}

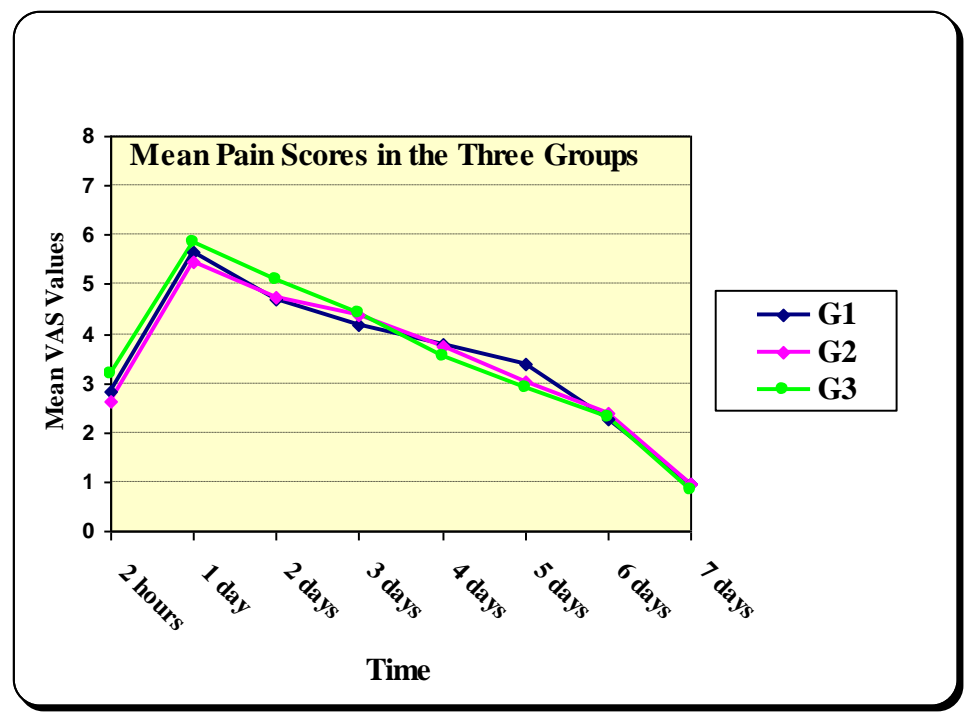

Fig. 1: Mean pain scores for the three age groups

\section{DISCUSSION}

Orthodontic patients may experience a considerable amount of discomfort from orthodontic treatment including feelings of tension, pressure, soreness of teeth, and pain. ${ }^{9}$ Pain is a subjective sensation and therefore difficult to measure. It is, however, important to quantify it for several reasons; one of the most compelling reasons is that assigning a measurement of pain gives patients some sense of control over their condition and has positive effects on their coping abilities. 
This study was performed on 45 patients who were to undergo fixed orthodontic treatment. The sample was divided into three groups included group 1 , the youngest; group 2, the middle; and group 3, the eldest. The severity of pain was recorded by the patient at two hours, 24 hours, 2days, and 3days and so on till the seventh day after wire ligation.

The visual analogue scale (VAS) is a well-studied method for measuring both acute and chronic pain, and its usefulness has been validated by several investigators. ${ }^{13,14,15}$

In order to investigate pain perceptions during orthodontic treatment, this study reports on three different age groups the pain response after the ligation of the first archwire. Because this is often the start of an orthodontic treatment, it is suggested that this can be used as a method to predict pain and compliance during treatment.

In this study females only were selected to participate to guard against any gender differences in pain response as reported in some studies. ${ }^{10,20}$

According to Furstman and Bernik ${ }^{4}$ pain during orthodontic treatment is a combination of pressure, ischemia, inflammation, and edema. Davidovitch and Shanfield ${ }^{21}$ noted that the early stages of orthodontic treatment involve an inflammatory response that shows periodontal vasodilatation and tenderness to pain.

Several studies have investigated pain frequently associated with orthodontic treatment. ${ }^{9-22}$ The present study showed that all patients experienced pain during treatment, and that the highest intensity was reached after one day from the start of archwire placement which is in accord with the results obtained by many investigators 9,10,11,22. Pain intensity gradually decreased, but the average pain levels were, however, low, at the seventh day, a finding which is in agreement with Scheurer et al. ${ }^{10}$, who reported $25 \%$ 'discomfort' (rather than pain) after one week.

In this current study, it was expected that there would be a difference in pain perception among the different age groups. However, no statistically significant differences was found in the three studied groups although the mean of pain VAS score was always the highest in the eldest group .This finding is in agreement with Kaneko et al., ${ }^{23}$ who used the pain index card for the first 14 days following placement of the first archwire in three age groups. He failed also to find any statistically significant differences between the three age groups 
studied. Again our findings are in accord with those of Scheurer et al. ${ }^{10}$ when they found that the pain intensity did not differ among the age groups.

In conflict to Kaneko et al., ${ }^{23}$ and also to our results ,the conclusions obtained by Jones ${ }^{7}$ in his study when he investigated the discomfort experienced by patients after placement of initial archwires, who found statistically significant higher discomfort experienced by adults compared with adolescents.

In addition to discouraging our patients to do their treatment it may influence the daily life. Brown and Moerenhout ${ }^{23}$ reported that pain from orthodontic appliances and its influence on daily life are seen as major causes of discontinuation of treatment. Also Aslihan et al. ${ }^{24}$, pointed out that the daily life of 50 per cent of the patients were influenced by the orthodontic wire at 6 hours and on days first and second days.

Our study indicated that there are no significant differences in pain response among the different age groups. This may support the concept that there are no age limitations for orthodontic treatment. Many clinicians now a day do treatment in advanced ages ${ }^{25-30}$ provided that there is a healthy periodontal condition.

\section{CONCLUSIONS}

1.All patients experienced pain during treatment.

2.Pain started two hours after ligation of the archwire.

3.Peak of pain intensity reported 24 hours after archwire ligation.

4.Pain intensity started to decline by the third day and reached the lowest level at seventh day.

5.There was no statistically significant difference in pain perception among the three age groups although the mean of pain experience was always the highest in the eldest group.

6. At the seventh day, $35 \%$ of the patients still recorded pain.

\section{REFERENCES}

1. Oliver RG, Knapman YM. Attitudes to orthodontic treatment. Br J Orthod. 1985;12:179-88.

2. Jones M., Chan C. Pain in the early stages of orthodontic treatment. J Clin Orthod. $1992 ; 26: 311-313$. 
3. Furstman, L. and Bernick, S.: Clinical Considerations of Periodontium, Am J Orthod. 1972; 61:138-155.

4. Soltis E, Nakfoor P, Bowman D. Changes in ability of patients to differentiate intensity of forces applied to maxillary central incisors during orthodontic treatment. J Dent Res.1971; 50:590-6.

5. Fujita K. A study on adaptability of the masticatory muscle after orthodontic treatment by measuring jaw closing force. Part I. Changes in maximum force of tolerance of each tooth during the tooth movement. J Kyushu Dent Soc. 1978; 31:413-7.

6. Burstone C. Mechanics: the biomechanics of tooth movement. In: Kraus B, Riedel R, eds. Vistas in orthodontics. Philadelphia:Lea \& Febiger, 1962:197-213.

7. Jones ML. An investigation into the initial discomfort caused by placement of an arch wire. Eur J Orthod. 1984; 6: 48- 54.

8. Jones ML, Richmond S. Initial tooth movement: force application and pain - a relationship? Am J Orthod. 1985;88:111-6.

9. Ngan P, Kess B, Wilson S. Perception of discomfort by patients undergoing orthodontic treatment. Am J Orthod Dentofacial Orthop. 1989; 96: 47-53.

10. Scheurer PA, Firestone AR, Burgin WB. Perception of pain as a result of orthodontic treatment with fixed appliances. Eur J Orthod. 1996; 18: 349-357.

11. Fernandes LM, Ogaard B, Skoglund L. Pain and discomfort experienced after placement of a conventional or a superelastic NiTi aligning archwire. A randomized clinical trial. J Orofac Orthop. 1998; 59: 331-339.

12. 12.Leavitt AH, King GJ, Ramsay DS, Jackson DL.A longitudinal evaluation of pulpal pain during orthodontic tooth movement. Orthod Craniofac Res. 2002 Feb; 5(1):29-37.

13. 13.Beecher HK 1959 Measurements of subjective responses. Oxford University Press. New York

14. 14.Joyce CRB, Zutshi DW, Hrubes V,Mason RM. Comparison of fixed interval and visual analogue scales for rating chronic pain. European Journal of Clinical Pharmacology 1975;8:415- 420.

15. 15.Huskisson EC. Visual analogue scale. In: Melzack R, ed. Pain measurement and assessment. New York: Raven Press, 1983: 33-7. Quoted from : Ngan P.,Wilson S.,Shanfield J. and Amini H.: The effect of ibuprofen on the level of discomfort in patients undergoing orthodontic treatment. Am J Orthod Dentofacial Orthop. 1994;106:88-95. 
16. 16.Sriwatanakul K,Kelvie W.Lasagna L, Calimlim JF,Weis OF, Mehta G . Studies with different types of visual analogue scales for measurement of pain. Clinical Pharmacology and Therapeutics 1983;34:234-239.

17. 17.Ngan P.,Wilson S.,Shanfield J. and Amini H.: The effect of ibuprofen on the level of discomfort in patients undergoing orthodontic treatment. Am J Orthod Dentofacial Orthop. 1994;106:88-95.

18. 18.Polat O; Karamanb AI; Durmusc E. Effects of Preoperative Ibuprofen and Naproxen Sodium on Orthodontic Pain. Angle Orthod. 2005;75:791-796.

19. 19.Proffit WR. Contemporary Orthodontics. 3rd ed. St Louis, Mo: Mosby; 2000:311-312.

20. 20.Kvam E, Gjerdet NR, Bondevik O. Traumatic ulcers and pain during orthodontic treatment. Community Dent Oral Epidemiol. 1987; 15: 104-107.

21. 21.Davidovitch Z, Shanfield J. Biochemical aspects of orthodontic tooth movement: cyclic nucleotide and prostaglandin concentrations in tissues surrounding orthodontically treated teeth in vivo. Am J Orthod Dentofacial Orthop.1986;90:139-148.

22. 22.Steen Law SL, Southard KA, Law AS, Logan HL, Jakobsen JR. An evaluation of preoperative ibuprofen for treatment of pain associated with orthodontic separator placement. Am J Orthod Dentofac Orthop 2000;118: 629-635.

23. Brown DF.Moerenhout RG.The pain experience and psychological adjustment to orthodontic treatment of preadolescents, adolescents and adults. Am J Orthod Dentofac Orthop 1991;100: 349-356.

24. Aslihan M. Erdinc E. and Dincer B. Perception of pain during orthodontic treatment with fixed appliances. Eur J Orthod. 2004; 26: 79-85.

25. Feng X. Oba T. Oba Y. Moriyama K. An interdisciplinary approach for improved functional and esthetic results in a periodontally compromised adult patient. Angle Orthod 2005; 75.6.1061-70

26. Seong-Min Bae and Hee-Moon Kyung. Mandibular molar intrusion with miniscrew anchorage. J Clin Orthod. 2006 ; 40:107-108.

27. Proffit W. Special considerations in comprehensive treatment for adults. In: Proffit W, Fields HW, eds. Contemporary Orthodontics.3rd ed. St Louis, Mo: Mosby; 2000:644-674. 
28. Ong MMA, Wang HL. Periodontic and orthodontic treatment in adults. Am J Orthod Dentofacial Orthop. 2002;122:420-428.

29. Melsen B, Agerbaek N, Markenstam G. Intrusion of incisors in adult patients with marginal bone loss. Am J Orthod Dentofacial Orthop. 1989;96:232-241.

30. Kalia S, Melsen B. Interdisciplinary approaches to adult orthodontic care. J Orthod. 2001;28:191-196. 